\title{
SBA-15 as a Support for Nickel-Based Catalysts for Polymerization Reactions
}

\author{
Anderson J. Schwanke, ${ }^{a}$ Cristiano Favero, ${ }^{b}$ Rosana Balzer, ${ }^{c}$ Katia Bernardo-Gusmão ${ }^{b}$ \\ and Sibele B. C. Pergher*,a \\ aPrograma de Pós-Graduação em Ciência e Engenharia de Materiais, Instituto de Química, \\ Universidade Federal do Rio Grande do Norte (UFRN), 59078-970 Natal-RN, Brazil \\ ${ }^{b}$ Instituto de Química, Universidade Federal do Rio Grande do Sul (UFRGS), \\ 91501-970 Porto Alegre-RS, Brazil \\ 'Departamento de Engenharias e Exatas, Universidade Federal do Paraná (UFPR), \\ 85950-000 Palotina-PR, Brazil
}

\begin{abstract}
Two mesoporous SBA-15 materials with different morphologies (spherical and fiber-shaped) were synthesized and evaluated as supports for nickel-based catalysts for polymerization reactions. The supports were pretreated with trimethylaluminum (TMA), and the catalyst dibromo-bis(4-amino-2,3,5,6-tetramethylimino)acenaphthene nickel(II) was attached to the supports and activated with TMA or MAO (methylaluminoxane). Characterization showed that the insertion of cetyltrimethylammonium bromide (CTABr) as a cosurfactant led to spherical SBA-15 with a decrease in particle and pore sizes to $4.8 \mathrm{~nm}$ compared to $6.5 \mathrm{~nm}$ in traditional fiber-shaped SBA-15. The spherical SBA-15 showed thicker walls than the fiber-shaped SBA-15, attributed to the increase in functional groups of the cosurfactant. The different spherical and fiber-shaped morphologies did not show any significant difference in the productivity of polyethylene. The catalyst supported on spherical SBA-15 materials showed $58 \%$ productivity compared to its homogeneous analogue using TMA as a cocatalyst.
\end{abstract}

Keywords: SBA-15, mesoporous, morphological control, polymerization

\section{Introduction}

The transition metal-catalyzed olefin polymerization reaction is very important in the chemical industry. ${ }^{1}$ Therefore, the nickel-based catalysts obtained by Brookhart and co-workers ${ }^{2}$ have been intensively studied. These catalysts have high catalytic activity and represent a pathway for traditional systems to polymerize polar monomers, obtaining control of the microstructure and promoting chain branching without the use of other monomers. However, polymerization in a homogeneous medium has the drawback of using a large volume of solvents and large reactors in which efficient control of temperature is required. ${ }^{3}$

Mesoporous silica materials have attracted great attention since their discovery in $1992 .{ }^{4,5}$ Among this class of materials, SBA-15 mesoporous silica has controllable large mesopore sizes $(5-15 \mathrm{~nm})$ with a narrow pore size

*e-mail: sibelepergher@gmail.com distribution and high surface area $\left(>500 \mathrm{~m}^{2} \mathrm{~g}^{-1}\right)$ and thick pore walls, leading to good stability. Therefore, SBA-15 materials have been applied in many fields, including catalysis, adsorption, separation, medicine and enzyme immobilization. ${ }^{6-10}$

The control of its structural properties relies on the synthesis conditions, e.g., temperature, stirring, micelle packaging parameters and the addition of cosurfactants and solvents. These modifications can lead to SBA-15 mesoporous material with different type-morphologies, including spheres, platelets, nanorods, rice shapes and hexagonal columns. ${ }^{11,12}$ Specifically, the application of mesoporous materials with spherical-shaped particles has been reported as drug delivery systems, the stationary phase in high-performance liquid chromatography (HPLC) columns and, recently, supports to metals in nickel and molybdenum-based catalysts. ${ }^{13-15}$ For all these applications, the spherical morphology showed higher performance than traditional fiber-shaped SBA-15 due to improved diffusion to the reactants or dispersion of the active centers. 
Other porous materials were used as supports for the polymerization of olefins, e.g., layered double hydroxides, silica-zirconia and silica-alumina supports and chrysotile. ${ }^{16-18}$ Mesoporous materials (MCM-41 and SBA-15) have previously been used as catalyst supports..$^{19,20}$ However, studies comparing the influence of different morphologies of the supports are infrequent. Here, we discuss the synthesis of spherical and fiber SBA-15 as supports for nickel-based catalysts for olefin polymerization and discuss parameters including the $\mathrm{Al} / \mathrm{Ni}$ ratio, volume of solvent, temperature and the aluminum activator.

\section{Experimental}

Synthesis of spherical and traditional fiber-shaped SBA-15 supports

The synthesis of spherical SBA-15 (sSBA-15) was performed using $2.0 \mathrm{~g}$ Pluronic P123 (tri-block copolymer poly(ethylene oxide)-poly(propylene oxide)poly(ethylene oxide)) and $0.2 \mathrm{~g}$ cetyltrimethylammonium bromide (CTABr, 99\%) dissolved in a mixture of $45.0 \mathrm{~g}$ deionized water, $30.0 \mathrm{~g} \mathrm{HCl}\left(2 \mathrm{~mol} \mathrm{~L}^{-1}\right)$ and $5.8 \mathrm{~g}$ tetraethyl orthosilicate (TEOS, 98\%). The mixture was stirred at $300 \mathrm{rpm}$ for $20 \mathrm{~h}$ at $40{ }^{\circ} \mathrm{C}$. The gel was transferred into a Teflon bottle and heated at $100{ }^{\circ} \mathrm{C}$ for $24 \mathrm{~h}$. The solid was filtered and dried at room temperature. The synthesis of traditional fiber-shaped SBA-15 (tSBA-15) was performed under the same conditions without the addition of CTABr. All reagents used were from Sigma-Aldrich. The samples were calcined (c) in nitrogen (gas flow $1 \mathrm{~cm}^{3} \mathrm{~s}^{-1}$ ) at $540{ }^{\circ} \mathrm{C}$ (heating rate of $3{ }^{\circ} \mathrm{C} \mathrm{min}^{-1}$ ). After reaching the temperature, nitrogen was replaced by synthetic air (gas flow $1 \mathrm{~cm}^{3} \mathrm{~s}^{-1}$ ) for $8 \mathrm{~h}$ at $540{ }^{\circ} \mathrm{C}$. The nitrogen and synthetic air used were from White Martins (grade 5.0).

\section{Pretreatment of the supports}

Within a suspension of the SSBA-15c or tSBA- $15 \mathrm{c}$ (1.4 g in $10.0 \mathrm{~mL}$ dry toluene, distilled over metallic sodium), $20 \mathrm{~mL}$ of a TMA solution in toluene $\left(1.5 \mathrm{mmol} \mathrm{mL} \mathrm{mL}^{-1}\right)$ was added. The reaction proceeded under magnetic stirring for $18 \mathrm{~h}$. The solid was removed by filtration under an inert atmosphere (argon) and washed consecutively with five aliquots of $15 \mathrm{~mL}$ toluene. The pretreated sSBA-15c and tSBA-15c were dried under reduced pressure and subsequently used for the immobilization of the catalytic precursor.

\section{Synthesis of the catalyst precursor}

The ligand was synthesized by the condensation reaction between acenaphthoquinone and 2,3,5,6-tetramethyl$p$-phenylenediamine, catalyzed by sulfuric acid. ${ }^{21}$ Then, the catalyst precursor was obtained by complexation of the ligand with a metal adduct of nickel(II) bromide and acetonitrile $\left(\mathrm{Ni}(\mathrm{MeCN})_{2} \mathrm{Br}_{2}\right)$ under argon atmosphere. Acetonitrile and dichloromethane were dried and distilled over $\mathrm{P}_{2} \mathrm{O}_{5}$ and stored under argon. The complexation reaction occurred at room temperature for $72 \mathrm{~h}$ in dichloromethane, as shown in Figure 1, for the formation of the homogeneous catalyst precursor dibromo-bis(4-amino-2,3,5,6-tetramethylimino) acenaphthene nickel(II), named $\mathrm{C} 1$.

\section{Immobilization of $\mathrm{C} 1$ on the pretreated supports}

The precursor was immobilized by adding $10 \mathrm{~mL}$ of a solution of $6.7 \mu \mathrm{mol} \mathrm{mL}-1$ of $\mathrm{C} 1$ in dichloromethane to a suspension containing $1.32 \mathrm{~g}$ of the pretreated $\mathrm{SSBA}-15 \mathrm{c}$ or tSBA-15c in $10 \mathrm{~mL}$ dichloromethane. The immobilization reaction was performed at room temperature for $18 \mathrm{~h}$. The original black solution turned into a clear solution after the reaction. The solvent was removed after completing the reaction, and the catalyst was directly used for the polymerization reactions. The nickel content SSBA-15c-C1 and tSBA-15c-C1 was determined by atomic absorption spectroscopy (AAS) with 96.7 and $97.5 \%$ of the original catalyst load $(67.4 \mu \mathrm{mol})$ anchored on the support, respectively.

\section{Polymerization reactions}

The polymerization reaction was carried out in a $200 \mathrm{~mL}$ glass jacketed reactor with a thermostatic circulation bath

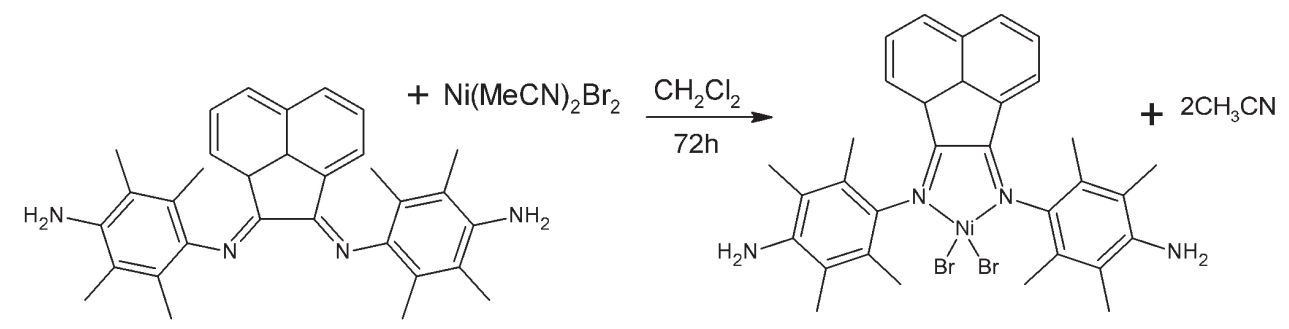

Figure 1. Synthesis of catalytic precursor dibromo-bis(4-amino-2,3,5,6-tetramethylimino)acenaphthene nickel(II), named C1. 
with controlled temperature. During the experiment, the reaction was homogenized by magnetic stirring. Dry toluene was used as the solvent and added to the reactor with a syringe under argon flow. The cocatalyst was added and stirred for five minutes. The system was purged five times with ethylene and saturated for five minutes. Finally, the precursor solution or the suspension of the heterogenized catalyst was added to the reactor after depressurization. The reaction started upon adding the precatalyst, kept under a continuous flow of ethylene at 4 bar. At the desired time, the polymer was precipitated in acidified ethanol $(5 \% \mathrm{HCl})$, washed consecutively with water and ethanol, filtered and dried under reduced pressure.

\section{Characterization}

Small-angle X-ray powder diffraction (XRD) was performed on a Bruker diffractometer, model D2 Phaser, with a Ni filter, $\mathrm{CuK} \alpha$ radiation $(\lambda=1.54 \AA$ ), and a voltage of $30 \mathrm{kV}$ using a Lynxeye detector. The scanning was performed at $2 \theta$ angles from 0.7 to $4.0^{\circ}$. The nitrogen adsorption and desorption isotherms at $-196{ }^{\circ} \mathrm{C}$ were obtained using a Micrometrics Tristar II (model 3020). The samples were pretreated under vacuum $\left(10^{-1} \mathrm{bar}\right)$ at $300{ }^{\circ} \mathrm{C}$ for $10 \mathrm{~h}$. The surface area of the samples was calculated by the BET (Brunauer-Emmett-Teller) equation, ${ }^{22}$ using relative pressure regions $\mathrm{p} / \mathrm{p}^{0}=0.05$ to 0.20 . The pore size distribution was calculated using the BJH (Barrett-Joyner-Halenda) method. ${ }^{23}$ Scanning electronic microscopy (SEM) analyses were performed using a Carl Zeiss scanning electron microscope model EVO50 operating in the variable pressure mode with an accelerating voltage of $5 \mathrm{kV}$ and a secondary electron detector. Transmission electron microscopy (TEM) analyses were performed using a Philips (model CM10) with an operating voltage of $100 \mathrm{kV}$. Atomic absorption spectroscopy (AAS) analyses were performed using a PerkinElmer A model Analyst 200. The polymers were characterized by differential scanning calorimetry (DSC) in a TA Instruments model Q20/RCS40 with cycles of heating and cooling. A small sample of polyethylene (5-10 mg) was heated and cooled at $10{ }^{\circ} \mathrm{C} \mathrm{min}{ }^{-1}$ over temperatures ranging from 30 to $180{ }^{\circ} \mathrm{C}$. Two cycles were performed, and the second cycle was used in our calculations for the crystallinity $(\chi c)$ and melting point (Tm).

\section{Results and Discussion}

The small-angle XRD and nitrogen adsorption and desorption isotherms of spherical and traditional fiber-shaped SBA-15 materials are shown in Figure 2. In general, the XRD patterns characteristic of long-range ordering are observed for both samples after calcination. The three diffraction bands are characteristic of planes 100, 110 and 200 with hexagonal symmetry. ${ }^{24}$

The XRD patterns of as-synthesized traditional fiber-shaped SBA-15 showed a contraction of $0.8 \mathrm{~nm}$ after calcination. This contraction is attributed to structural rearrangements by dehydration, dehydroxylation and the
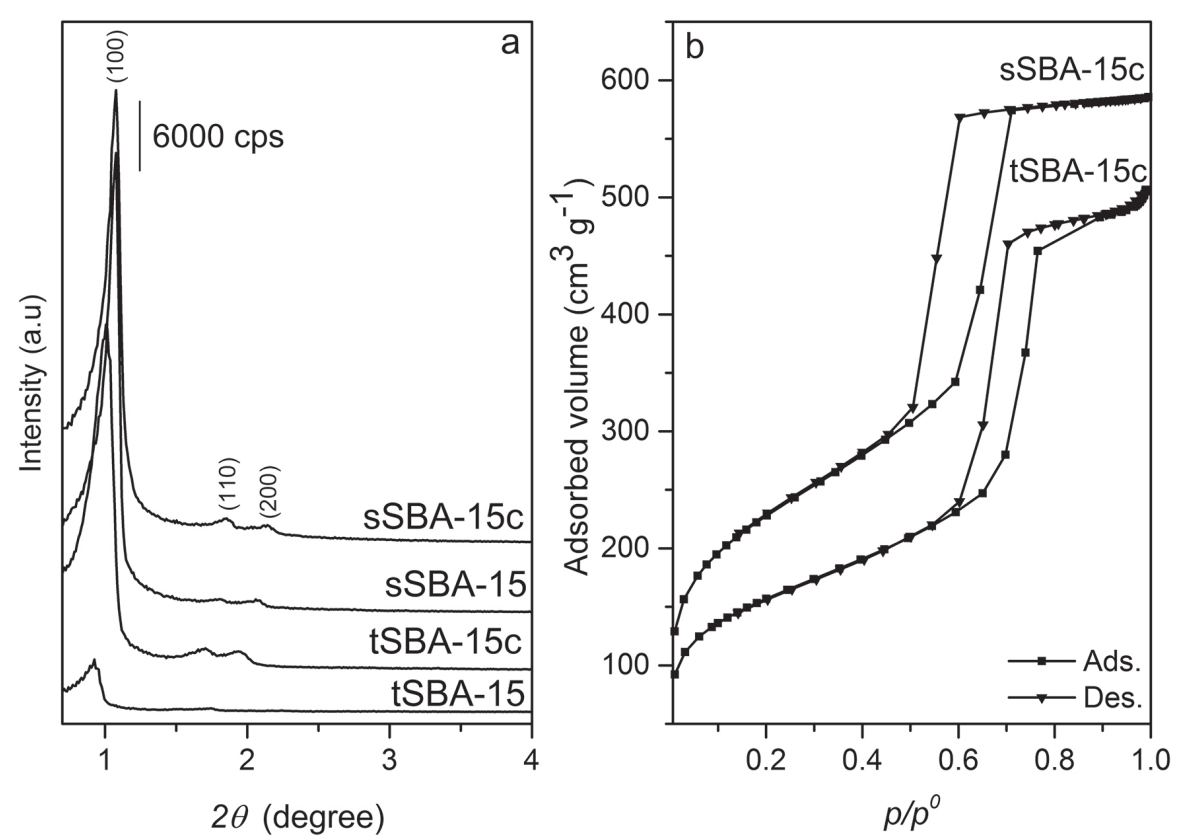

Figure 2. Small-angle XRD of as-synthesized and calcined spherical and traditional fiber-shaped SBA-15 (a) and nitrogen adsorption and desorption isotherms of calcined samples (b). 
Table 1. Textural properties of traditional and spherical SBA-15 calcined materials

\begin{tabular}{|c|c|c|c|c|c|c|c|c|c|}
\hline Sample & $\mathrm{d}_{100} / \mathrm{nm}$ & $\mathrm{a}_{0} / \mathrm{nm}$ & $\mathrm{S}_{\mathrm{BET}} /\left(\mathrm{m}^{2} \mathrm{~g}^{-1}\right)$ & $\mathrm{S}_{\text {micro }} /\left(\mathrm{m}^{2} \mathrm{~g}^{-1}\right)$ & $\mathrm{S}_{\mathrm{ext}} /\left(\mathrm{m}^{2} \mathrm{~g}^{-1}\right)$ & $\mathrm{V}_{\text {micro }} /\left(\mathrm{cm}^{3} \mathrm{~g}^{-1}\right)$ & $\mathrm{V}_{\text {meso }} /\left(\mathrm{cm}^{3} \mathrm{~g}^{-1}\right)$ & $\mathrm{D}_{\mathrm{p}} / \mathrm{nm}$ & $\mathrm{W}_{\mathrm{t}} / \mathrm{nm}$ \\
\hline sSBA-15c & 8.7 & 10.1 & 819 & 134 & 685 & 0.05 & 0.9 & 4.8 & 5.3 \\
\hline tSBA-15c & 8.8 & 10.2 & 558 & 101 & 457 & 0.04 & 0.8 & 6.5 & 3.7 \\
\hline
\end{tabular}

$\mathrm{a}_{0}$ : lattice parameters $=2 \mathrm{~d}_{100} / \sqrt{3} ; \mathrm{S}_{\mathrm{BET}}:$ BET surface area; $\mathrm{S}_{\text {micro }}$ : microporous surface area; $\mathrm{S}_{\text {ext }}$ : external surface area; $\mathrm{V}_{\text {micro }}$ : microporous volume; $\mathrm{V}_{\text {meso }}$ : mesoporous volume; $\mathrm{D}_{\mathrm{p}}$ : pore diameter; $\mathrm{W}_{\mathrm{t}}$ : wall thickness $=\mathrm{a}_{0}-\mathrm{D}_{\mathrm{p}}$.

formation of siloxane bonds, producing a silica with a more condensed structure. ${ }^{25}$ However, this contraction did not occur for as-synthesized and calcined spherical SBA-15 samples.

The nitrogen adsorption and desorption isotherms for spherical and traditional fiber-shaped SBA-15 are shown in Figure 2b. Both calcined materials showed type IVa isotherms, characteristic of mesoporous materials, according to IUPAC. ${ }^{26}$ The abrupt increase in the adsorbed amount of nitrogen at $\mathrm{p} / \mathrm{p}^{0}$ ranging from 0.6 to 0.8 corresponds to the region of capillary condensation within the uniform mesopores. Both SBA-15 samples exhibit type $\mathrm{H} 1$ hysteresis with irreversible cycles related to the geometry of well-ordered open cylindrical pores. ${ }^{26}$ The pore diameter showed values centered at 4.8 and $6.5 \mathrm{~nm}$ for the spherical and traditional fiber-shaped SBA-15 materials, respectively.

Table 1 shows the textural properties of spherical and traditional fiber-shaped SBA-15. The spherical SBA-15 showed a surface area $\left(\mathrm{S}_{\mathrm{BET}}\right)$ of $819 \mathrm{~m}^{2} \mathrm{~g}^{-1}$, and the traditional fiber-shaped SBA-15 showed $558 \mathrm{~m}^{2} \mathrm{~g}^{-1}$. Both samples have similar values of the microporous surface area $\left(S_{\text {micro }}\right)$, which interconnects the mesoporous channels.

It was observed that the lattice parameters $\left(a_{0}\right)$ for spherical and traditional fiber-shaped SBA-15 samples are similar. However, the pore diameter of spherical SBA-15 is $1.7 \mathrm{~nm}$ smaller than for traditional fiber-shaped SBA-15. We attributed this to the increase in functional groups (provided by cosurfactant, CTABr) with nonionic P123 copolymer, attracting more silica species and producing a material with an increased wall thickness. Indeed, similar behavior was reported by Ryoo and co-workers ${ }^{27}$ for the synthesis of mesoporous silica. The increased wall thickness $\left(\mathrm{W}_{\mathrm{t}}\right)$ for spherical SBA-15 increases the stability of the material. On the other hand, the decrease in pore diameter could limit the access of the catalytic precursor.

SEM images of spherical and traditional fiber-shaped SBA-15 materials are shown in Figure 3. Homogeneous spheres were observed with sizes ranging from 0.5 to $2.5 \mu \mathrm{m}$ (images a and $\mathrm{b}$ ), clearly different from traditional fiber-shaped SBA-15 (images c and d). The synthesis of SBA-15 with the single copolymer P123 leads to a

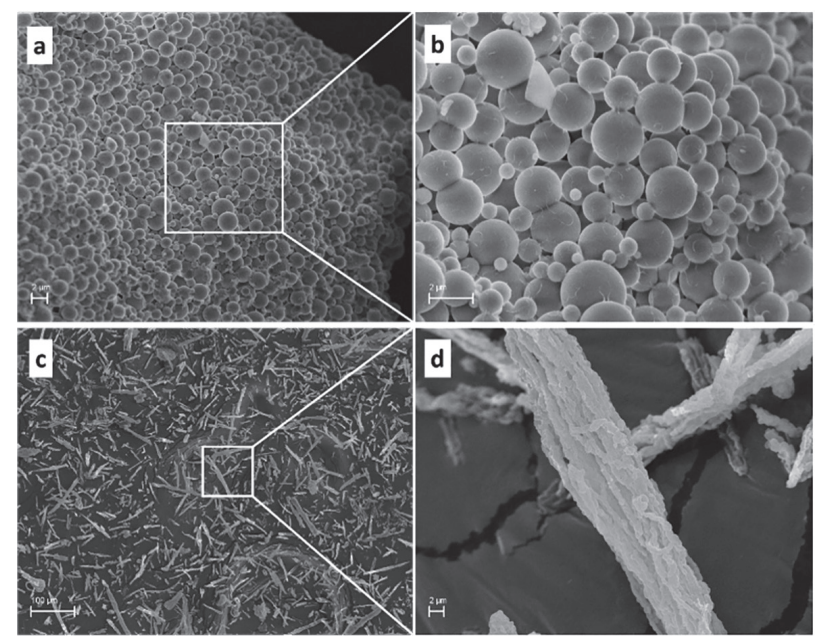

Figure 3. SEM of spherical sSBA-15c with magnifications of (a) 5,000x and (b) $15,000 \times$. Images of traditional tSBA-15c with magnifications of (c) $300 \times$ and (d) $5,000 \times$.

fiber-shaped morphology of the agglomerated particles with lengths and widths ranging between 80-100 $\mu \mathrm{m}$ and 3-9 $\mu \mathrm{m}$, respectively.

The TEM analyses of spherical and traditional fiber-shaped SBA-15 materials are shown in Figure 4, and the hexagonal honeycomb pore structure was observed for both samples. In addition, the measurements of pore size and pore walls are in good agreement with the related XRD and nitrogen adsorption results. Figure 5 summarized the proposed assembly of single P123 and mixed P123-CTABr
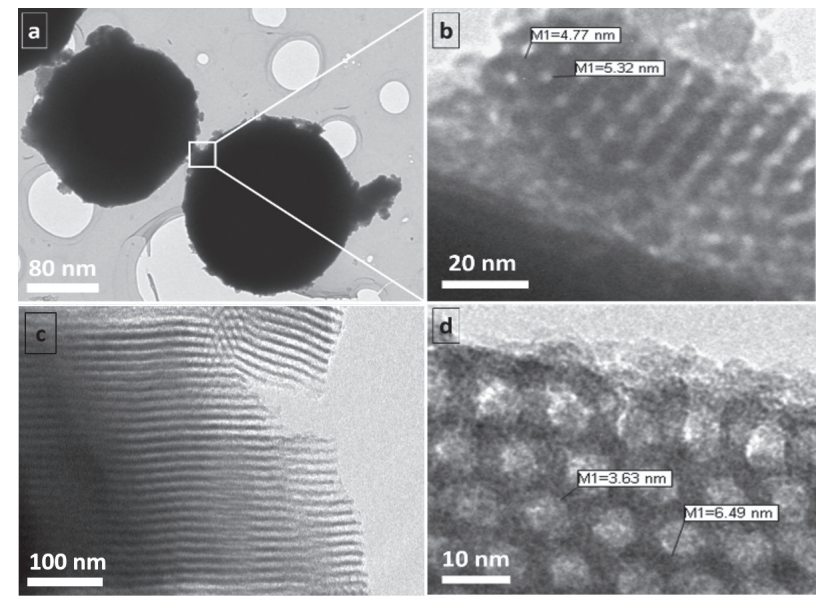

Figure 4. TEM of spherical sSBA-15c (a, b) and traditional fiber-shaped tSBA-15 (c, d). 


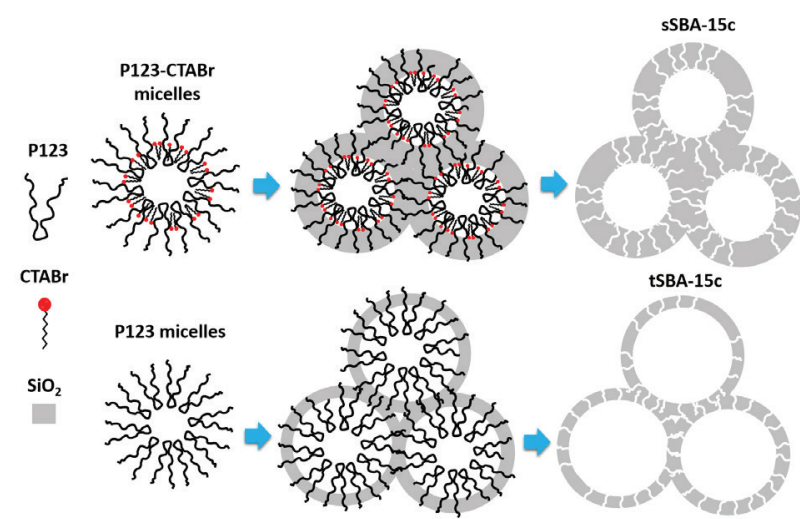

Figure 5. Proposed assembly of single $\mathrm{P} 123$ or mixed P123-CTABr micelles and the final spherical and traditional SBA-15 mesoporous structure.

micelles for the formation of the final SBA-15 mesoporous structure.

The spherical and traditional fiber-shaped SBA-15 materials were used as supports for heterogenization of the catalyst precursor $\mathrm{C} 1$, and the results of the polymerization reactions are shown in Table 2. In general, the precursor $\mathrm{C} 1$ was heterogenized on the spherical (entry 5) and traditional fiber-shaped (entry 4) SBA-15 with a partial decrease in catalytic activity compared to the homogeneous precursor C1 (entry 1). The sSBA-15c-C1 showed $72 \%$ of the homogeneous productivity, and tSBA-15-C1 showed 74\%, indicating that both the supports and the methodology of heterogenization were appropriate. Due to the morphological differences between spherical and traditional fiber-shaped SBA-15, the pore diameter sSBA- $15 \mathrm{c}$ is $1.7 \mathrm{~nm}$ smaller than in tSBA-15c. On the other hand, the surface area of sSBA-15c is higher $\left(261 \mathrm{~m}^{2} \mathrm{~g}^{-1}\right)$ than $\mathrm{tSBA}-15 \mathrm{c}$, which is related to the smaller particle size of sSBA-15c, which resulted in shorter channels. Thus, shorter channels may allow access of the monomer and cocatalyst to the active centers and compensate for the small pore sizes of sSBA-15c, giving similar results in terms of polyethylene productivity.

Due to this similarity, other reaction conditions were used with spherical SBA- $15 \mathrm{c}-\mathrm{C} 1$ and are reported in entries 5 to 12 . One benefit related to the use of the heterogenized catalysts is their applicability in more advantageous processes such as gas phase or slurry polymerization. ${ }^{21}$ Therefore, the solvent volume used in each experiment was evaluated (entries 5 and 6). The results showed that even in more concentrated or diluted experiments, the catalytic activity remained constant. In addition, the crystallinity was also constant, which demonstrates that the heterogenized precursor could be used for other processes with a smaller volume of solvent without a decrease in catalytic activity. The effect of the activator (MAO or TMA) is shown in entries 7-8 and 9-10. For the reaction system, TMA proved to be a better activator at lower temperatures $\left(30^{\circ} \mathrm{C}\right)$, while $\mathrm{MAO}$ was better at $60^{\circ} \mathrm{C}$. In addition, polymers with higher crystallinity were produced using TMA than MAO.

Entries 6 and 7 show an increase of productivity with decreasing reaction time, where the catalyst is more active in the first minutes. On the other hand, increasing the temperature of the reaction (entries 5,9 and 10) led to a decrease in the polymerization rate, with a drop in activity for the homogeneous and heterogeneous systems and for both cocatalysts. Similar behavior has been reported in the literature. ${ }^{28}$ The $\mathrm{Al} / \mathrm{Ni}$ ratio for both catalysts was also

Table 2. Results of the polymerization reaction with both heterogenized SBA-15c-C1 and homogeneous nickel-based catalyst C1

\begin{tabular}{|c|c|c|c|c|c|c|c|c|c|c|}
\hline System & entry & time / min & $\mathrm{T} /{ }^{\circ} \mathrm{C}$ & Cocatalyst & $\mathrm{Al} / \mathrm{Ni}$ & Solvent / mL & $\mathrm{PE} / \mathrm{g}$ & $\begin{array}{c}\text { Productivity / } \\
\left(\mathrm{kg} \text { PE mol Ni }{ }^{-1} \mathrm{~h}^{-1}\right)\end{array}$ & $\chi c / \%$ & $\mathrm{Tm} /{ }^{\circ} \mathrm{C}$ \\
\hline \multirow{3}{*}{ Homogeneous $\mathrm{C} 1$} & 1 & 30 & 30 & MAO & 325 & 60 & 3.7 & 2437 & 14 & 125 \\
\hline & 2 & 10 & 30 & TMA & 325 & 30 & 2.3 & 4510 & 18 & 125 \\
\hline & 3 & 10 & 60 & TMA & 325 & 30 & 0.4 & 960 & $\mathrm{NF}$ & $\mathrm{NF}$ \\
\hline tSBA-15c-C1 & 4 & 30 & 30 & MAO & 325 & 60 & 2.8 & 1811 & 33 & 120 \\
\hline \multirow{8}{*}{ sSBA-15c-C1 } & 5 & 30 & 30 & MAO & 325 & 60 & 2.7 & 1751 & 28 & 121 \\
\hline & 6 & 30 & 30 & MAO & 325 & 30 & 2.5 & 1641 & 29 & 122 \\
\hline & 7 & 10 & 30 & MAO & 325 & 30 & 0.9 & 1858 & 28 & 120 \\
\hline & 8 & 10 & 30 & TMA & 325 & 30 & 1.3 & 2613 & 38 & 129 \\
\hline & 9 & 10 & 60 & TMA & 325 & 30 & 0.3 & 722 & 11 & 122 \\
\hline & 10 & 10 & 60 & MAO & 325 & 30 & 0.4 & 936 & 7 & 116 \\
\hline & 11 & 10 & 30 & TMA & 55 & 30 & 0.5 & 1084 & 31 & 128 \\
\hline & 12 & 10 & 30 & MAO & 55 & 30 & 0.3 & 641 & 37 & 122 \\
\hline
\end{tabular}

Reaction conditions: $200 \mathrm{~mL}$ reactor with control of temperature and stirring. Ethylene pressure 4 bar, MAO or TMA solution and $3.1 \mu \mathrm{mol}$ of catalytic precursor. PE: polyethylene; $\chi$ c: crystallinity; Tm: melting point; NF: not found. 
varied (entries 11 and 12), and the results showed that even at very low $\mathrm{Al} / \mathrm{Ni}$ ratios, moderate activity was achieved. Two distinct melting points were found for entry 11, suggesting a bimodal distribution of the polymeric chains under these conditions.

The catalyst precursor $\mathrm{C} 1$ supported on spherical SBA-15 showed 58\% activity compared to the homogeneous catalyst at $30{ }^{\circ} \mathrm{C}$ (entries 2 and 8) and similar activity at higher temperatures (entries 3, 9 and 10). The system showed better performance with TMA as cocatalyst than MAO (entries 7 and 8).

\section{Conclusions}

Two mesoporous SBA-15 silica materials with different morphologies were synthesized. The use of $\mathrm{CTABr}$ as a cosurfactant produced spherical SBA-15 with smaller particles and pore sizes than traditional fiber-shaped SBA-15. Both SBA-15 supports were efficient catalytic supports for a nickel-based catalyst precursor, with similar activity. The activity for the catalyst supported on spherical SBA- 15 was $72 \%$ for $30 \mathrm{~min}$ of reaction and $58 \%$ for $10 \mathrm{~min}$ of reaction compared with the homogeneous analogue. Under different reaction conditions, the supported catalysts exhibit more stable active centers, enhancing the catalytic activity. The precursor was active under adverse conditions such as less solvent and lower $\mathrm{Al} / \mathrm{Ni}$ ratios.

\section{Acknowledgments}

The authors acknowledge the support provided by UFRN, UFRGS and CNPq.

\section{References}

1. Coates, G. W.; Waymouth, R. M.; Science 1995, 267, 217.

2. Johnson, L. K.; Killian, C. M.; Brookhart, M.; J. Am. Chem. Soc. 1995, 117, 6414.

3. Severn, J. R.; Chadwick, J. C.; Duchateau, R.; Friederichs, N.; Chem. Rev. 2005, 105, 4073.

4. Kresge, C. T.; Leonowicz, M. E.; Roth, W. J.; Vartuli, J. C.; Beck, J. S.; Nature 1992, 359, 710.

5. Beck, J. S.; Vartuli, J. C.; Roth, W. J.; Leonowicz, M. E.; Kresge, C. T.; Schmitt, K. D.; Chu, C. T. W.; Olson, D. H.; Sheppard, E. W.; J. Am. Chem. Soc. 1992, 114, 10834.

6. Zhao, D.; Feng, J.; Huo, Q.; Melosh, N.; Fredrickson, G. H.; Chmelka, B. F.; Stucky, G. D.; Science 1998, 279, 548.

7. Zhou, L.; Fan, J.; Cui, G.; Shang, X.; Tang, Q.; Wang, J.; Fan, M.; Green Chem. 2014, 16, 4009.
8. Timm, J.; Stoltenberg, C.; Senker, J.; Bensch, W.; Z. Anorg. Allg. Chem. 2014, 640, 595.

9. Bahrami, Z.; Badiei, A.; Atyabi, F.; Chem. Eng. Res. Des. 2014, 92, 1296.

10. Yiu, H. H. P.; Wright, P. A.; Botting, N. P.; J. Mol. Catal. B: Enzym. 2001, 15, 81.

11. Lee, H. I.; Kim, J. H.; Stucky, G. D.; Shi, Y.; Pak, C.; Kim, J. M.; J. Mater. Chem. A 2010, 20, 8483.

12. Zhao, D.; Sun, J.; Li, Q.; Stucky, G. D.; Chem. Mater. 2000, $12,275$.

13. Lai, C.-Y.; Trewyn, B. G.; Jeftinija, D. M.; Jeftinija, K.; Xu, S.; Jeftinija, S.; Lin, V. S. Y.; J. Am. Chem. Soc. 2003, 125, 4451.

14. Yasmin, T.; Müller, K.; J. Chromatogr. A 2011, 1218, 6464.

15. Gao, D.; Duan, A.; Zhang, X.; Zhao, Z.; E, H.; Li, J.; Wang, H.; Appl. Catal., B 2015, 165, 269.

16. Buffet, J.-C.; Wanna, N.; Arnold, T. A. Q.; Gibson, E. K.; Wells, P. P.; Wang, Q.; Tantirungrotechai, J.; O'Hare, D.; Chem. Mater. 2015, 27, 1495.

17. Silveira, F.; Brambilla, R.; da Silveira, N.; Alves, M. C. M.; Stedile, F.; Pergher, S. C.; dos Santos, J. H. Z.; J. Mater. Sci. 2010, 45, 1760.

18. Silveira, F.; Alves, M. C. M.; Stedile, F. C.; Pergher, S. B.; dos Santos, J. H. Z.; J. Mol. Catal. A: Chem. 2010, 315, 213.

19. Ramachandra Rao, R.; Weckhuysen, B. M.; Schoonheydt, R. A.; Chem. Commun. 1999, 5, 445.

20. Casas, E.; van Grieken, R.; Escola, J. M.; Appl. Catal., A 2012, 437-438, 44.

21. Preishuber-Pflugl, P.; Brookhart, M.; Macromolecules 2002, 35, 6074 .

22. Brunauer, S.; Emmett, P. H.; Teller, E.; J. Am. Chem. Soc. 1938, $60,309$.

23. Barrett, E. P.; Joyner, L. G.; Halenda, P. P.; J. Am. Chem. Soc. 1951, 73, 373.

24. Meynen, V.; Cool, P.; Vansant, E. F.; Microporous Mesoporous Mater. 2009, 125, 170.

25. Bagshaw, S. A.; Bruce, I. J.; Microporous Mesoporous Mater. 2008, 109, 199.

26. Thommes, M.; Kaneko, K.; Neimark, A. V.; Olivier, J. P.; Rodriguez-Reinoso, F.; Rouquerol, J.; Sing, K. S. W.; Pure Appl. Chem. 2015, 87, 1051.

27. Lee, J.-S.; Joo, S. H.; Ryoo, R.; J. Am. Chem. Soc. 2002, 124, 1156.

28. Choi, Y.; Soares, J. B. P.; Macromol. Chem. Phys. 2009, 210, 1979.

Submitted: April 9, 2017

Published online: August 1, 2017

FAPERGS/CAPES has sponsored the publication of this article. 